\title{
Experimental Study on the Ignition Process of Single Coal Particles at Microgravity
}

\author{
Gen-tu Tang • Hai Zhang • Ming-ming Zhu • \\ Hairui Yang • Guang-xi Yue • \\ Shuangfeng Wang · Xinshi Wan
}

Received: 30 January 2008 / Accepted: 18 October 2008 / Published online: 12 November 2008

(C) Springer Science + Business Media B.V. 2008

\begin{abstract}
In this paper, the first Chinese microgravity $(\mu-g)$ experimental study on coal combustion was introduced. An experimental system used to study the ignition process of single coal particles was built up, complying with the requirements of the $3.5 \mathrm{~s}$ drop tower in the National Microgravity Laboratory of China (NMLC). High volatile bituminous and lignite coal particles with diameter of 1.5 and $2.0 \mathrm{~mm}$ were tested. The ignition and combustion process was recorded by a color $\mathrm{CCD}$ and the particle surface temperature before and at the ignition was determined by the RGB colorimetric method. Comparative experiments were conducted at normal gravity (1-g). The experiments revealed that at different gravity levels, the ignition of all tested coal particles commenced in homogeneous phase, while the shape, structure, brightness and development of the flames, as well as the volatile matter release during the ignition process are different. At $\mu-g$, the part of volatile was released as a jet, while such a phenomenon was barely observed at 1-g. Also, after ignition, flames were more spherical, thicker, laminated and dimmer at $\mu$-g. It was confirmed that
\end{abstract}

G.-t. Tang · H. Zhang (凶) $\cdot$ M.-m. Zhu .

H. Yang - G.-x. Yue

Key Laboratory for Thermal Science and Power

Engineering of Ministry Education,

Department of Thermal Engineering,

Tsinghua University, Beijing, 100084 China

e-mail: haizhang@tsinghua.edu.cn

S. Wang $\cdot$ X. Wan

National Microgravity Laboratory, Institute of Mechanics,

Chinese Academy of Science, Beijing, China

S. Wang

e-mail: sfwang@imech.ac.cn ignition temperature decreased as the particle size or volatile content increased. However, contradicted to existing experimental results, provided other experimental conditions except gravity level were the same, ignition temperature of coal particles was about $50-80 \mathrm{~K}$ lower at $\mu-g$ than that at $1-g$.

Keywords Microgravity $\cdot$ Single coal particle $\cdot$ Ignition process $\cdot$ Ignition temperature $\cdot$ Drop tower

\section{Introduction}

When a coal particle is heated up, pyrolysis process occurs and part of the volatile content in the particle is released. And then, ignition happens given oxygen is present around the particle. It can happen in gaseous phase, as the volatile content keeps accumulating around the particle, or on particle surface as the temperature and oxygen concentration is sufficiently high. Fully understanding such a process is very important for designing and modeling burner, combustor and gasifier, and preventing from unwanted fire.

Due to its importance and complexity, the ignition process of coal particles has been being studied for generations. Previous studies showed that this process is influenced by a few factors, including coal type (Annamalai and Durbetaki 1977; Karcz et al. 1980; Tognotti et al. 1985; Gieras et al. 1986a, b; Essenhigh et al. 1989; Gururajan et al. 1990; Du and Annamalai 1994; Zhang and Wall 1994; Chen et al. 1994; Davini et al. 1996; Katalambula et al. 1996, 1997a, b; Yang et al. 2005), particle size (Annamalai and Durbetaki 1977; Karcz et al. 1980; Tognotti et al. 1985; Gieras et al. 1986a, b; Essenhigh et al. 1989; Gururajan et al. 
1990; Du and Annamalai 1994; Zhang and Wall 1994; Chen et al. 1994; Davini et al. 1996; Katalambula et al. 1996, 1997a, b), oxygen concentration (Annamalai and Durbetaki 1977; Karcz et al. 1980; Tognotti et al. 1985; Gieras et al. 1986a, b; Essenhigh et al. 1989; Gururajan et al. 1990; Zhang and Wall 1994; Chen et al. 1994), heating rate (Gieras et al. 1986b; Essenhigh et al. 1989; Gururajan et al. 1990; Du and Annamalai 1994; Zhang and Wall 1994; Katalambula et al. 1997b; Yang et al. 2005), experimental technique (Tognotti et al. 1985; Zhang and Wall 1994; Chen et al. 1994; Yang et al. 2005), and particle shape (Wendt et al. 1999, 2002). In the same time, many data were obtained and several models have been developed.

However, more recently, it was found that the ignition process can be also influenced by buoyancyinduced natural convection, or called buoyancy effect (Gieras et al. 1986a, b; Katalambula et al. 1997b; Wendt et al. 1999, 2002). The natural convection can impact the molecular transport and heat transfer around and inside the particle, and sweep the surrounding volatile cloud away.

To minimize the buoyancy effect during coal ignition, microgravity $(\mu-g)$ experiments are desired (Ronney 2001). Through these experiments, one can not only reveal the unique scientific phenomena as for the other $\mu$ - $g$ combustion studies, but also provide ideal data to validate the existing models. The later one is of particular significance since in nearly all existing models, the natural convection is neglected by taking it for granted while the results are compared with experimental data obtained at normal gravity $(1-g)$.

So far, a number of $\mu-g$ experiments have been conducted on ignition and combustion of gases and liquid oil, but rarely on coal, neither on single coal particles, nor on particle clouds (Ronney 2001; Zhang 2004). Pioneering $\mu-g$ experiments on coal combustion of single or individual particles was conducted by Gieras et al. (1986a, b) in 1980s, on flame propagation and mutual interaction between burning particles, with direct and Schlieren photographing. However, neither data of ignition temperature and ignition time, nor comparisons with normal-gravity $(1-g)$ were reported. In the mid 1990s, Katalambula et al. (1997b) conducted some $\mu-g$ experiments on the ignition of single coal particles. Ignition temperature, time, volatile matter released of single coal particle with different size and coal type were assessed. It was found that in $\mu-g$ condition coal particle ignition commenced homogeneously and then heterogeneously for all testing samples with diameter in a range of 0.8 to $1.2 \mathrm{~mm}$, and the ignition temperature was higher and ignition time was longer than those in $-1 g$ condition. It was suggested that the difference is due to the weaker diffusion transport at $\mu-g$. However, the temperature measurement method by using a set of fine $\mathrm{Pt} / \mathrm{Pt}-\mathrm{Rh}$ type thermocouple coiled around the particle used in their experiments was questionable. Obviously, the bean of the thermocouples could not ideally be attached to particle surface, and the thermocouples could be an effective catalyst for the homogeneous ignition reaction. Moreover, the thermocouples could interact with the flow field, behaving differently at $1-g$ and $\mu-g$. Wendt et al. (1999) conducted more experiments on the shape effect on ignition at $\mu-g$ with the same experimental method.

Beside the temperature measurement, how to support and ignite the coal particle in $\mu-g$ experiments is another issue. In experiments by Gieras et al. (1986a, b), the particles separated in a certain distance were adhered to quartz needles fixed on organic glass plates. The first coal particle was ignited from a drop of $n$-octane of 1-mm diameter. Obviously, such experimental setup could introduce remarkable errors due to the influence of ignition oil and support plate on the coal particles. Thus, the results are doubtable to be used to validate ignition models of single coal particles. In the experiments conducted by Katalambula et al. (1997b), the coal particle was heated up and then ignited by radiant radiation with specially designed spot heaters. Though quantitative heating rate was supplied, the environmental temperature was low, differing from the hot furnace configuration in which most of coals is practically burnt. The particle, placed on the joint of the coiled thermocouples, could be difficult to be precisely fixed at the focus point of spot heaters.

The objective of this study is to use an improved experimental system and temperature measurement method to assess the ignition behaviors of single coal particle at $\mu-g$, and compare the results with the ones obtained at $1-g$.

\section{Experimental}

Experiments were conducted in the drop tower recently built in the National Microgravity Laboratory of China (NMLC), Beijing, China. The effective $\mu-g$ time was about $3.5 \mathrm{~s}$ and the $\mu-g$ level was about $10^{-2} \sim 10^{-3} \mathrm{~g}$. Figure 1 shows a side-viewed picture of the experimental apparatus and Fig. 2 shows the schematics of the entire system. The system consists of a tube furnace, a coal particle feeding device, a PLC controller, an image and data recording device and auxiliary power supply. The furnace is in dimension of $\Phi 25 \times 300 \mathrm{~mm}$, heated by AC electricity with the power of $200 \mathrm{~W}$. During the 


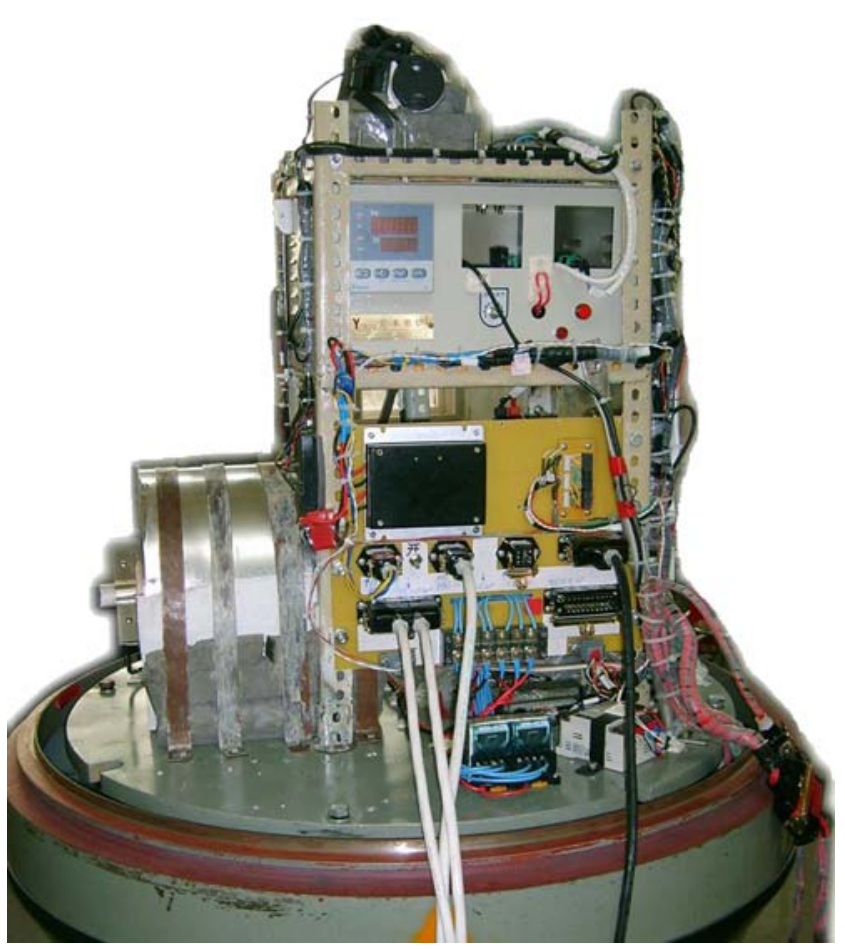

Fig. 1 Experimental apparatus for single coal particle ignition

experiment, a single coal particle was glued at the tip of a fine glass fiber with high-temperature inorganic glue. The glass fiber was mounted on the mechanism of a linear motor which could quickly translate the particle in and out of the furnace.

The apparatus was enclosed in a standard capsule used in NMLC during the drop. Before the drop, the furnace was heated up by external power, and after the apparatus was enclosed, its temperature was maintained by a set of internal DC batteries. A DC-AC converter was used to convert the DC power into AC power. The furnace temperature was set to $1123 \mathrm{~K}$ during the experiments. Right before the drop, the particle was sent into the furnace to preheat for $1.0-1.5 \mathrm{~s}$ to ensure ignition happens at $\mu$-g. It was calibrated that the heating rate of the testing particles at the furnace

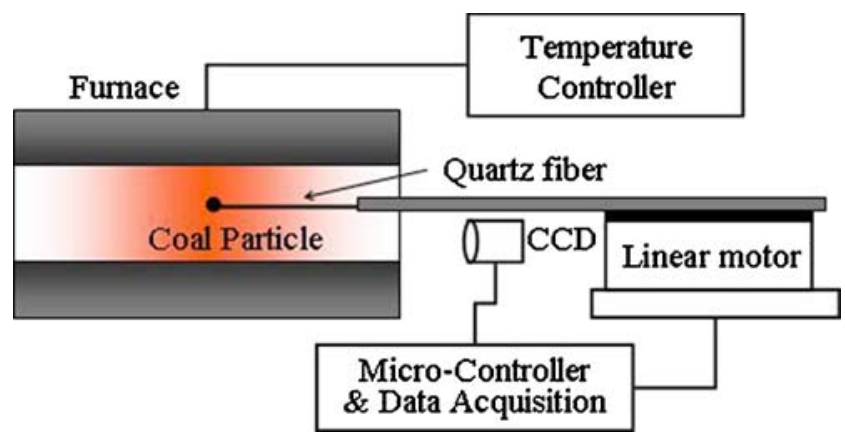

Fig. 2 The schematic of experimental system
Table 1 Proximate analysis of coal samples

\begin{tabular}{lllll}
\hline Sample & $\begin{array}{l}\text { Moisture } \\
\left(M_{\mathrm{ad}} \%\right)\end{array}$ & $\begin{array}{l}\text { Ash } \\
\left(A_{\mathrm{ad}} \%\right)\end{array}$ & $\begin{array}{l}\text { Volatile } \\
\left(V_{\mathrm{ad}} \%\right)\end{array}$ & $\begin{array}{l}\text { Fixed } \\
\text { carbon } \\
\left(\mathrm{FC}_{\mathrm{ad}} \%\right)\end{array}$ \\
\hline DTB & 3.1 & 21.9 & 31.3 & 43.7 \\
SDB & 6.3 & 4.1 & 29.1 & 60.5 \\
HLL & 13.1 & 4.3 & 38.1 & 44.5 \\
\hline
\end{tabular}

temperature of $1,123 \mathrm{~K}$ was about $200-300 \mathrm{~K} / \mathrm{s}$. The preheating would raise the particle temperature to a value less than $600 \mathrm{~K}$ such that no volatile content in the coal was released.

The selection of particle size and coal type was limited by current experimental conditions. It was difficult to mount small particles on the tip of the fine fiber. Thus, the diameters of 1.5 and $2.0 \mathrm{~mm}$ were chosen. Ground experiments found that the ignition time of mm-sized, low volatile lean or anthracite coal particles was usually more than $5 \mathrm{~s}$. Consequently, three high volatile coals were selected, and they were Datong bituminous (DTB), Sandaocha bituminous (SDB) and Huolinhe lignite (HLL) respectively. The proximate and ultimate analyses of the tested coals were given in Table 1.

The entire ignition and burning process of the particle was recorded with a color CCD camera, with a frequency of 25 frames per second. The images visually showed the flame shape, flame radius, and their temporal development. At $\mu$ - $g$, flame was usually spherical, and thus its radius was defined as the flame standoff from the solid surface and the burning of the solid phase. In this study, the flame standoff was determined

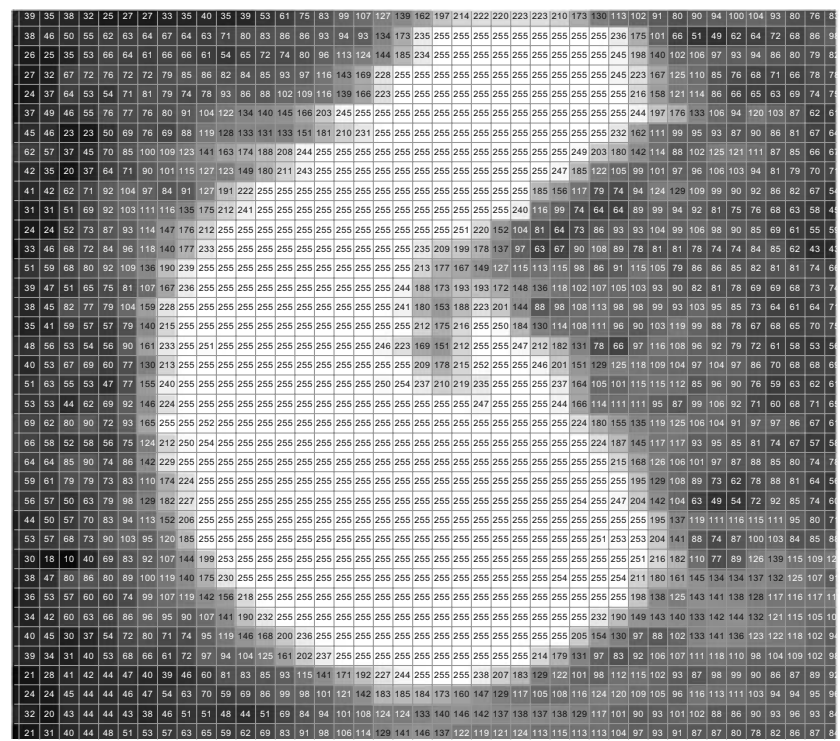

Fig. 3 Typical flame image processed by MATLAB 
by pixel-based image processing. The flame was defined to be located at the pixel whose energy density was of a maximum value in the radial direction. Figure 3 is a typical image of the flame after digital processing with MATLAB. The left part is influence by the fiber holder.

Theoretically, it could be assumed that any color image of a radiative object is uniquely composed by three single colors, red $(R)$, green $(G)$ and blue $(B)$, representing the radiative intensity at corresponding wavelength (Wei et al. 1998; Zhou 2005). Thus, the two values of RGB can be used as the comparative colors in the traditional twin color pyrometry (Gururajan et al. 1990). In our experiments, the $R$ and $G$ values were used, and the kind of non-intrusive temperature determination method is called RGB colorimetric method.

Using the calibration with a black body furnace, the linear relationship between $1 / T$ and $\ln (R / G)$ can be obtained. Then according to the measured $R$ and $G$ values, the temperature of the pixel can be derived. It should be pointed out that this method was not with high accuracy for burning and low temperature particles. For the burning particles, the image becomes saturated. For low temperature particles, below $700 \mathrm{~K}$, the emission is weak and mostly in infrared ray region. However, some emission is still in the visual light region. Figure 4 shows the image and $G$ color pixel value distribution for the coal particle before ignition at temperature about $650 \mathrm{~K}$. It can be seen the particle is rather dark and only through image processing the color can be distinguished. The emission of the gases before the ignition could be neglect compared with that emitted from the solid surface. For our experiments, the ignition temperature was normally around or above $700 \mathrm{~K}$, thus it was still convenient and with acceptable accuracy for ignition temperature determination. It was estimated the error of the method for ignition temperature determination was within $\pm 15 \mathrm{~K}$.
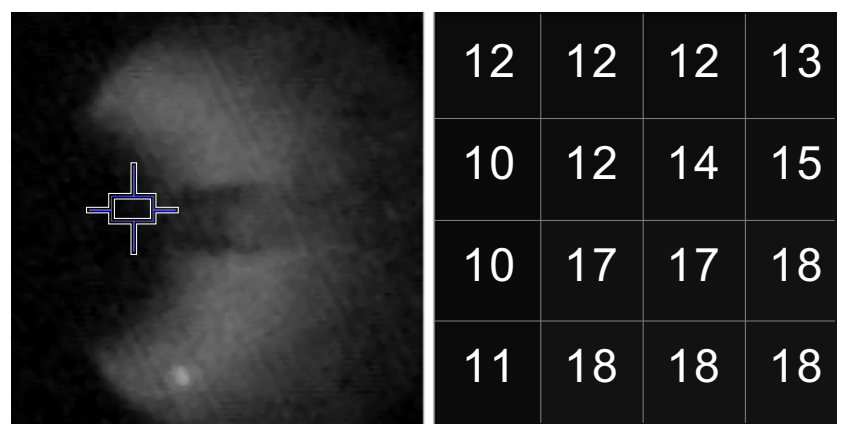

Fig. 4 Typical single color value distribution for the coal particle before ignition (left: image, right: green color pixel value, $T=\sim 650 \mathrm{~K}$ )

\section{Results and Discussion}

Ignition of Single mm-sized Particles at $\mu-g$

Figures 5 and 6 are selected pictures showing the ignition process of $\Phi 1.5 \mathrm{~mm}$ DTB and $\Phi 2.0 \mathrm{~mm}$ HLL coal particles at $\mu-g$ and $1-g$ respectively. The color difference of background furnace was because at $\mu-g$ the system was enclosed and at $1-g$ the system was open to the environment. The background color would not the affect phenomena observation and data analysis. It can be seen that a flame appears before the surface combustion commences. Namely, the coal ignition is of homogeneous type under the testing conditions at both $\mu-g$ and $1-g$. At $\mu-g$, this ignition process however is quite different than at $1-g$, and some interesting phenomena are observed.

The entire process can divided into three phases: beginning phase, intermediate phase, and ending phase.

The first two are related to ignition and the last one is combustion only. In the beginning phase, e.g., in the first $200 \mathrm{~ms}$ after ignition, the flame is irregularly shaped, neither of spherical shape, nor of an upward tail like the one at $1-g$. The irregular shape of the flame can be attributed to the non-uniform evolution of the volatile content around the particle surface. The gravity effect in this phase is disturbed by the jet-type volatile release.

Shortly after the beginning phase is the intermediate phase, in which the flame becomes spherical, enclosing the solid particle. At the same time, flame volume increases and then decreases after a certain period. Compared with the $1-g$ flames at the same moment after ignition, it can be seen that $\mu-g$ flames are more spherical, thicker, more laminated and dimmer. When buoyancy effect is minimized, the transport becomes weaker but more isotropic. The burning intensity becomes weaker as well. Correspondingly, at 1-g, the flame shape is strongly affected by the buoyancy. Flame center is offset upwardly. The top of the flame shape is of a pear (Fig. 5b) or a tulip (Fig. 6b). The difference may be depended on the coal properties. Flames are also brighter due to the stronger molecular transport introduced by the natural convection.

It can also be seen from Fig. $5 \mathrm{a}$, for the $\Phi 1.5 \mathrm{~mm}$ DTB particles, some protuberances are clearly observed on the outer surface of the flame during the intermediate phase. The results indicate that some volatile was released in jets, very probably from the pores or cracks of the coal particles. The protuberance in the intermediate phase is severer than that in the beginning phase, indicating that the combustion of volatile content in the gas phase around the coal 


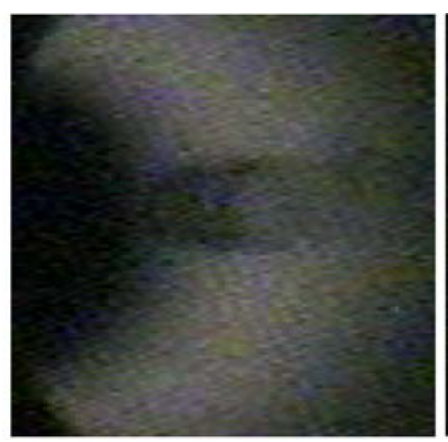

a (0-s)

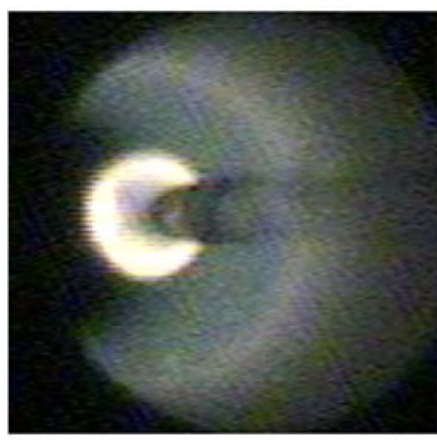

$\mathrm{a}(600 \mathrm{~ms})$

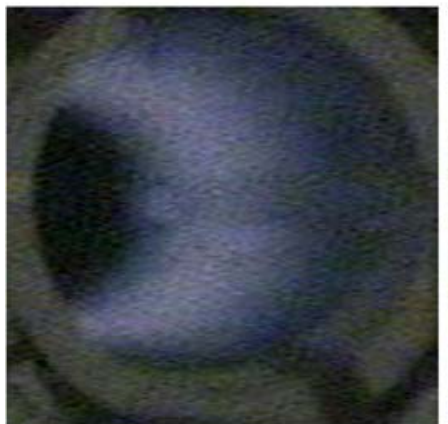

b (0-s)

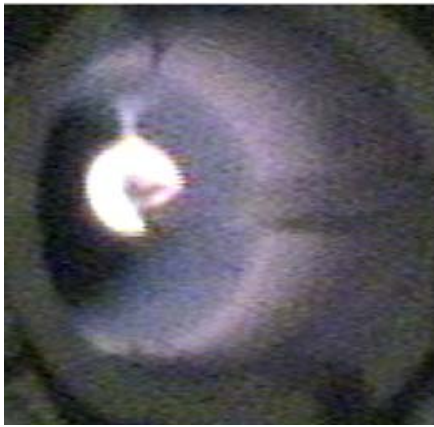

b (600ms)

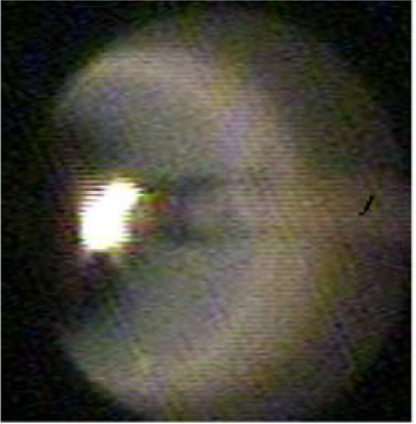

$\mathrm{a}(0+\mathrm{s})$

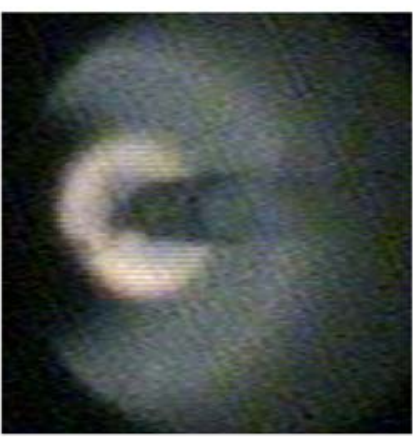

$\mathrm{a}(800 \mathrm{~s})$

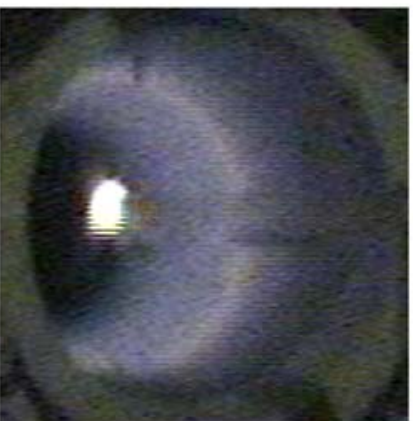

$\mathrm{b}(0+\mathrm{s})$

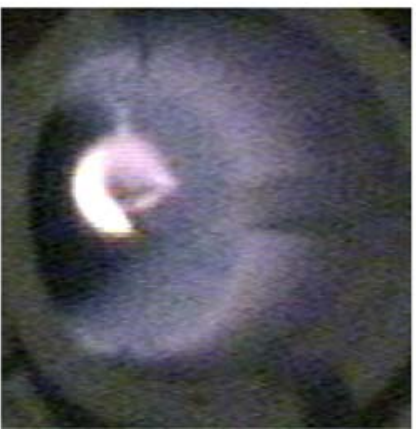

b (800ms)

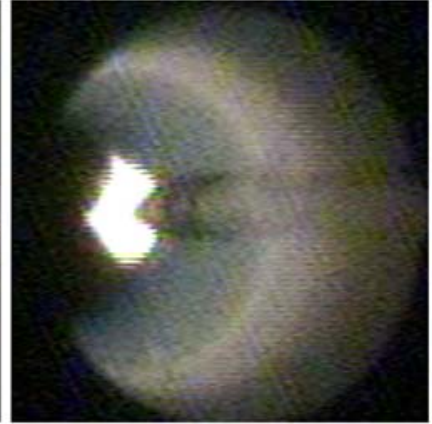

a (200ms)

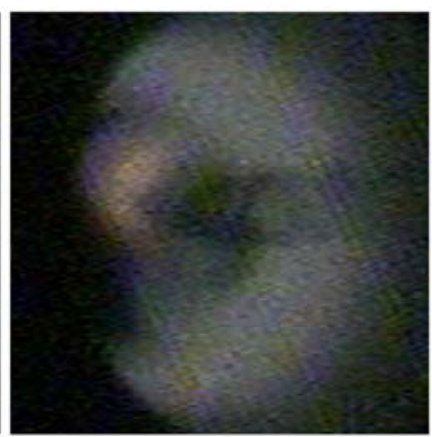

a (1000ms)

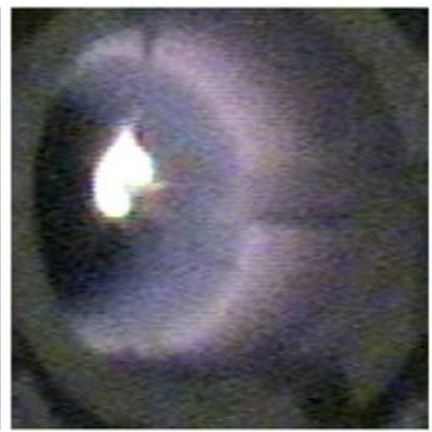

b (200ms)

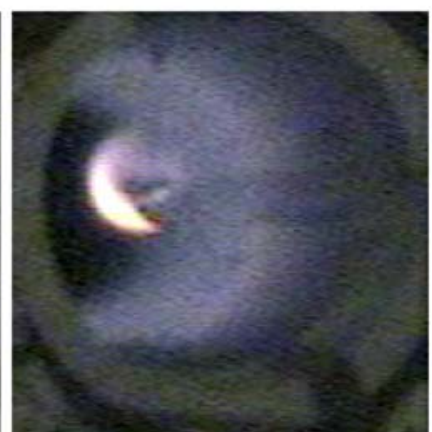

b (1000ms)

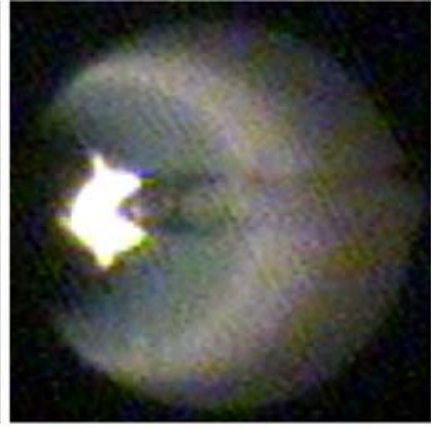

a (400ms)

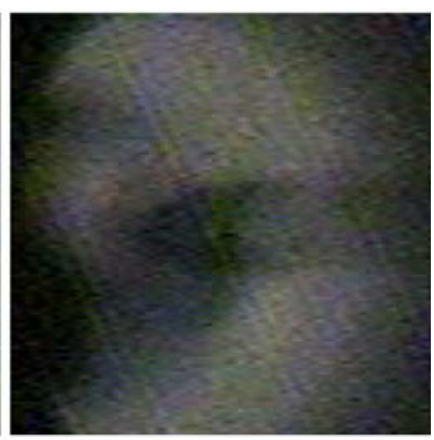

a (1200ms)

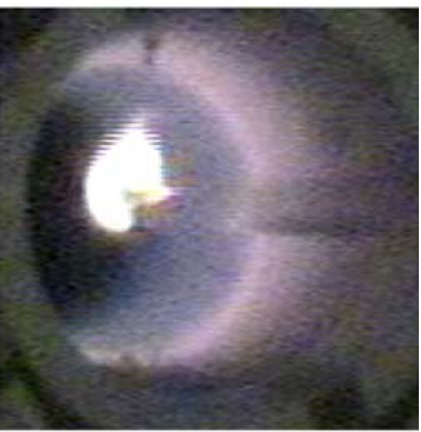

b (400ms)

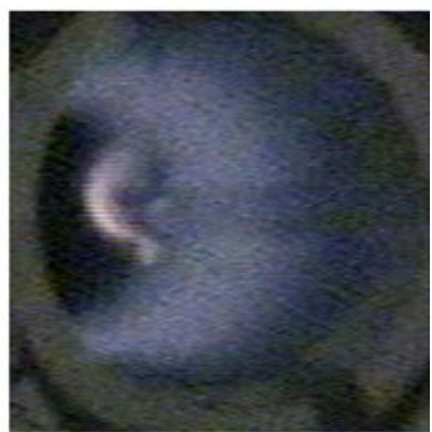

b (1200ms)

Fig. 5 Selective photos taken in single coal particle ignition and burning process for DTB coal with diameter of $1.5 \mathrm{~mm}$ under microgravity (a), normal gravity (b), time starts at ignition 


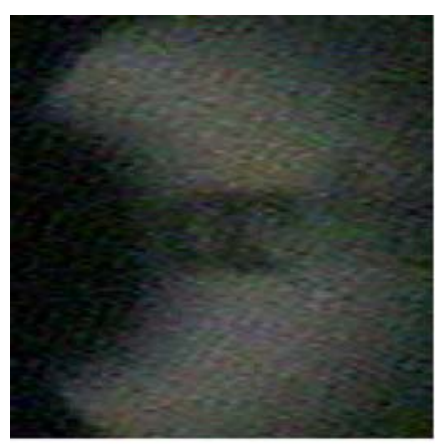

a $(0-s)$

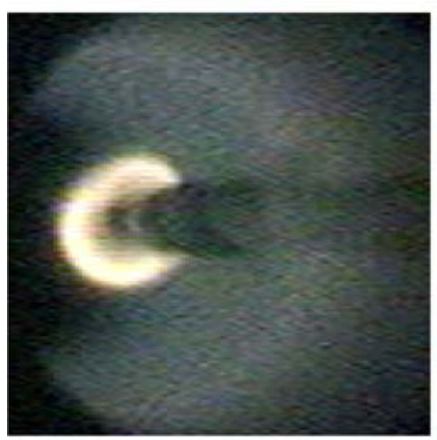

$\mathrm{a}(600 \mathrm{~ms})$

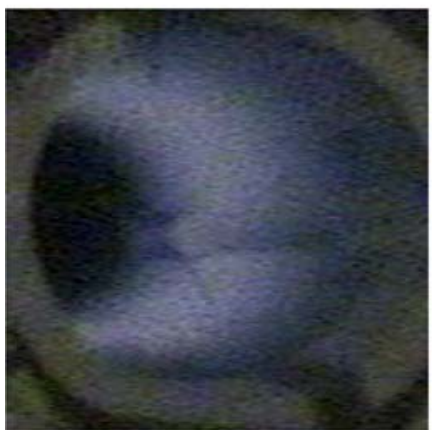

b (0-s)

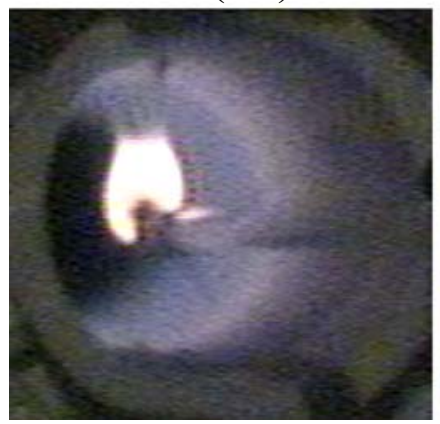

b (600ms)

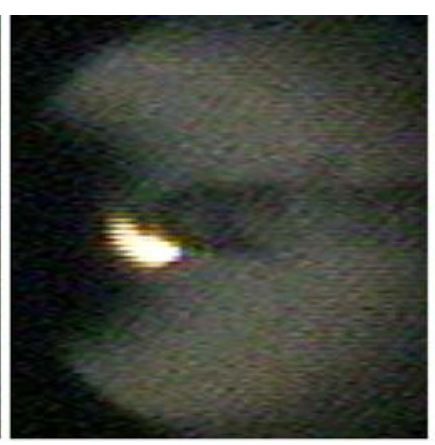

$\mathrm{a}(0+\mathrm{s})$

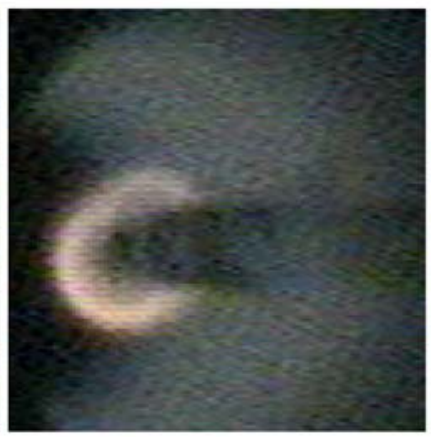

a (800s)

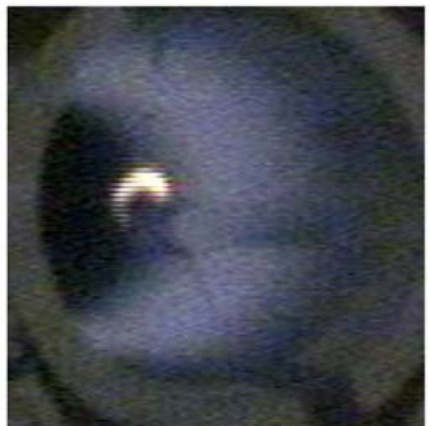

b $(0+s)$

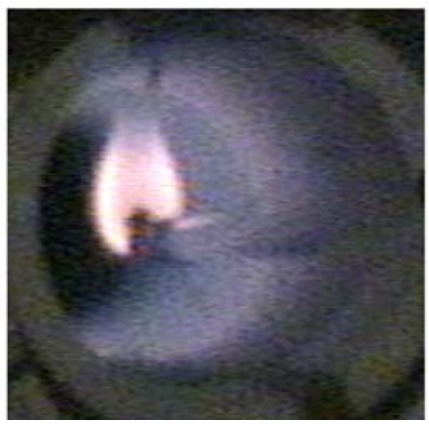

b (800ms)

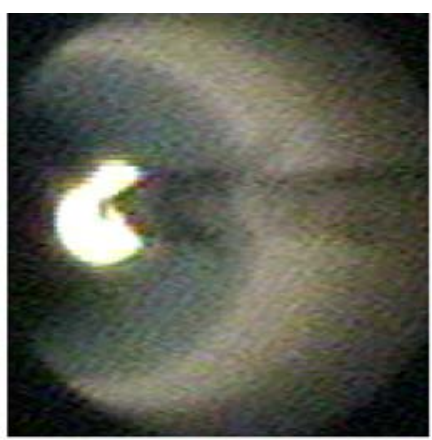

$\mathrm{a}(200 \mathrm{~ms})$

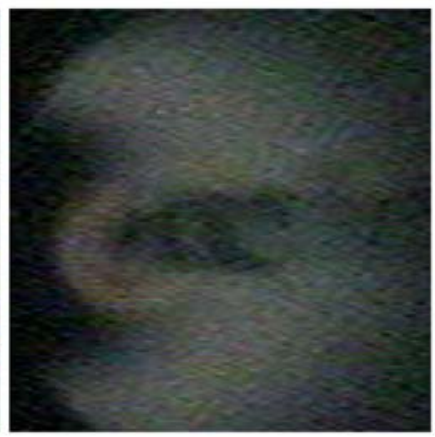

a (1000ms)

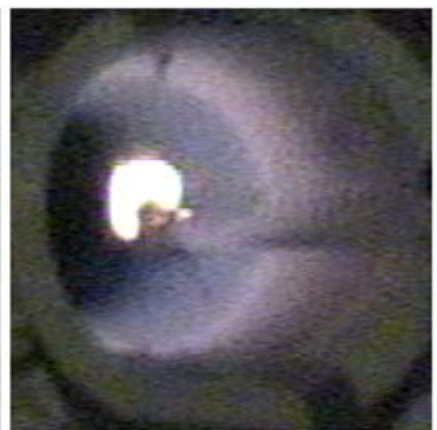

b (200ms)

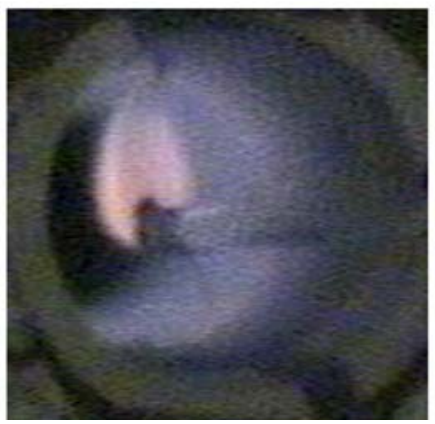

b (1000ms)

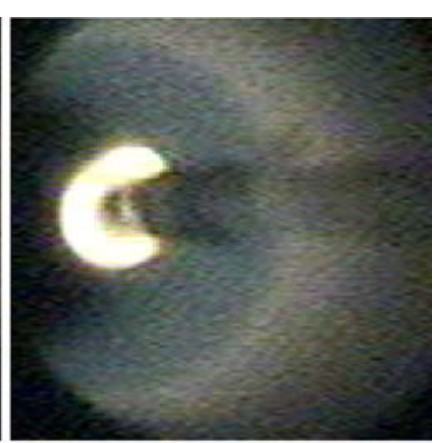

a (400ms)

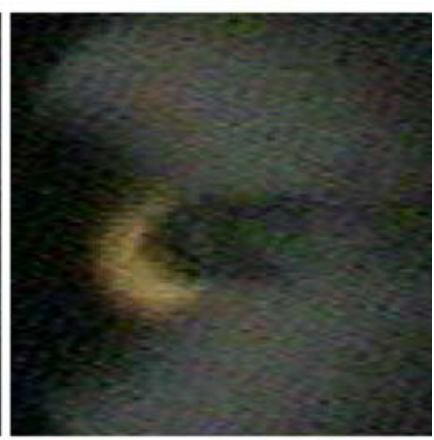

$\mathrm{a}^{*}(2600 \mathrm{~ms})$

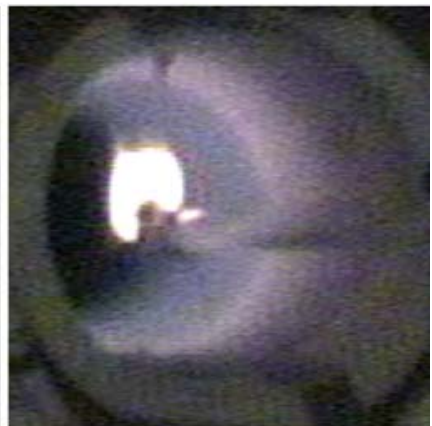

b (400ms)

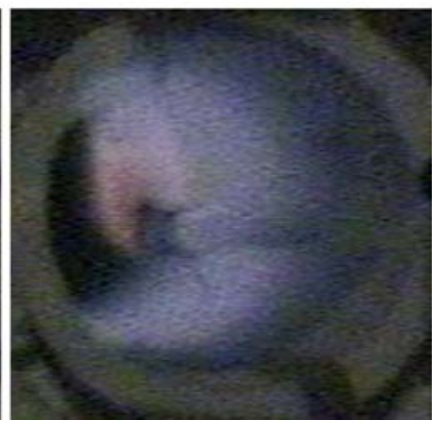

b (1200ms)

Fig. 6 Selective photos taken in single coal particle ignition and burning process for HLL coal with diameter of 2.0 mm under microgravity (a) normal gravity (b), time starts at ignition. *Second Ignition when the drop was finished at 1-g

particle further facilitates the release of rest volatile content. However, protuberances were only found for DTB at $\mu-g$ under present experimental conditions.
At 1-g, it was expected the jet-type devolatilization still existed for DTB but was covered by the natural convection. While for some coals like HLL, even with 
high volatile content, due to their special pore structure, heating value, volatile and moisture content etc, jettype devolatilization was not obvious.

A certain period after ignition, the flame starts to shrink, and the particles experience combustion only phase, i.e. the ending phases. Comparing the figures at the same moment for $\mu-g$ and $1-g$, it can be seen that the gravity effect in this phase is significantly strong. At 1-g, the flame keeps bright for rather long time. Heterogeneous combustion, commencing in the intermediate phase lasts in this phase, and extinction happens as the char particle is burnt out. When the environment is free of natural convection, at $\mu-g$, the molecular transport of the oxidizer to the flame front and the products (e.g., $\mathrm{CO}_{2}$ and $\mathrm{H}_{2} \mathrm{O}$ ) becomes weaker. Thus, the burning intensity is lower; thereby the flame is dimmer. Furthermore, it can be found that close to extinction, in the center of the spherical flame, there is a large dark spot, indicating that combustion barely continues in the heterogeneous phase. In addition, the flames are of clear multiple color layers. Given $\mu-g$ time is enough long, a remarkable part of the particle would remain unburnt, even though its surface temperature would be high. The last two images in Fig. 6a show that ignition re-occurs right after the rig reached at $1-g$ environment, and this is called the second ignition. This result indicates that the buoyancy effect is beneficial for the coal particle combustion.

Ignition Temperatures at $\mu-g$ and at $1-g$

Figure 7 shows the temporal variations of the surface temperature determined by the RGB colorimetric

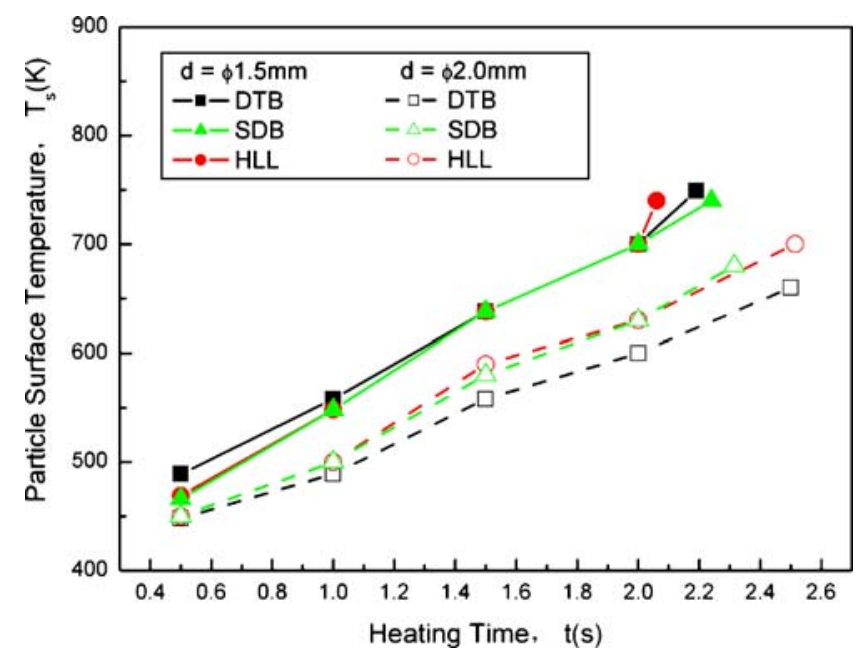

Fig. 7 The temporal variation of surface temperature of the coal particle before ignition

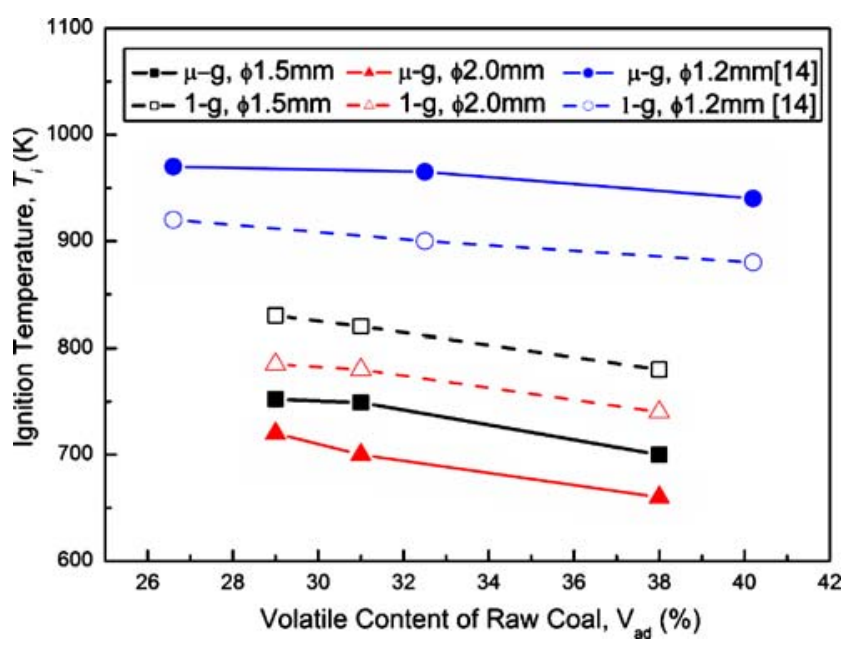

Fig. 8 The variation of ignition temperature of the coal particle with volatile content

method for test coals at $\mu-g$. Though the error in the low temperature region could be rather big with this method as we discussed before, the trends are clear. It can be seen that the heating rate for the particle before ignition is in the range of $130 \sim 160 \mathrm{~K} / \mathrm{s}$. The smaller is the particle, the larger rate is. This is reasonable since when the particle is heated by radiation, the heat adsorption is proportional to surface area in $d^{2}$, while the temperature variation is proportional to the particle mass in $d^{3}$. The trends are consistent with those found by Katalambula et al. (1997b), but present heating rate was about half smaller.

Based on above temporal temperature variations, together with the image record by high speed CCD, it is easily to find out the value of temperature at the

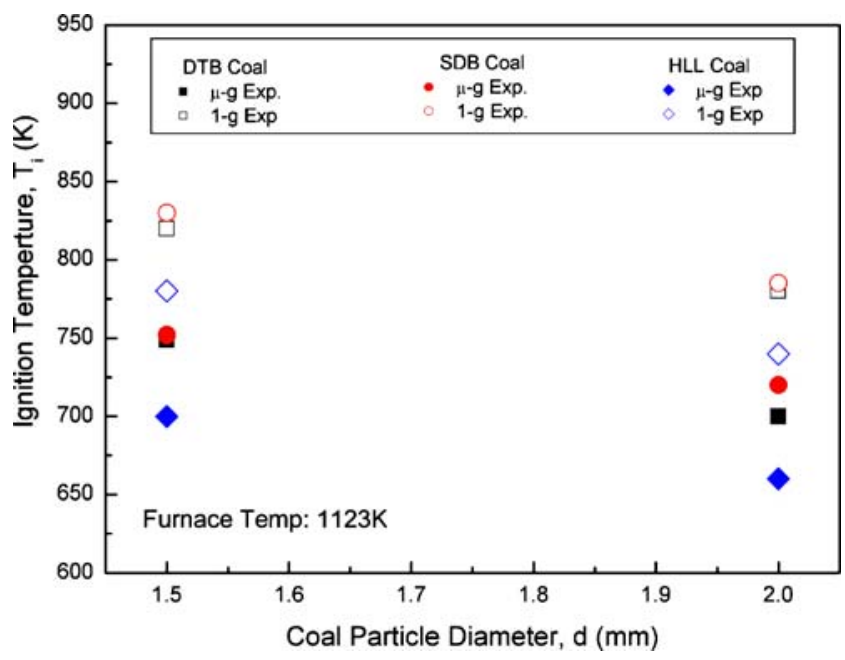

Fig. 9 The variation of ignition temperature of the coal particle with particle size 
moment a flame appeared near the coal particle. This temperature, as a common practice, is defined as the ignition temperature.

Figure 8 shows the variations of ignition temperature with the volatile content for test coal particles at $\mu-g$ and $1-g$ respectively. Both existing literature and present experiments show that ignition temperature decreases with the increasing volatile content. For coal particles with the same size, the higher is the volatile content, the higher concentration of the combustible gaseous around the particle during the pyrolysis process is and thus the easier ignition happens. However, opposed to what was found in previous experiments (Katalambula et al. 1997b), the ignition temperatures at $\mu-g$ for the same coal with the same size is about 50 $80 \mathrm{~K}$ lower than the $1-g$ ones, rather than higher than the $1-g$ ones. This is reasonable since the diffusion is weaker at $\mu-g$ than at $1-g$, and thus the evolved volatile matter accumulates more and heavier around the coal particle. At 1-g, the natural convection will sweep part of evolved volatile matter away from the surface. The diffusion enhancement introduced by the buoyancy is overwhelmed. The temperatures in previous experiments (Katalambula et al. 1997b) were remarkably higher than the corresponding present data. It seems that temperatures measured in the previous study were closer to the ones of gaseous phase.

It is worth to remind that though buoyancy effect rises the ignition temperature but it is helpful to enhance the combustion intensity as we discussed in the last section.

Figure 9 depicts the ignition temperatures at different particle diameter for three tested coal particles at $\mu-g$ and $1-g$ respectively. Consistent with previous studies (e.g., Essenhigh et al. 1989; Katalambula et al. 1997b), present experiments show that at both $\mu-g$ and 1-g, ignition temperature decreases with the particle size for a given coal. For the mm-sized particles, ignition occurs homogeneously, especially at $\mu-g$, depending on the volatile matter concentration surrounding the particles. The smaller is diameter, the higher the volatile matter concentration is. Furthermore, it can be seen that the two bituminous coals have close ignition temperature while the lignite coal HLL has slightly lower values. Nevertheless, for both sizes, the ignition temperatures at $\mu-g$ are lower than the corresponding $1-g$ ones.

Experiments also found the ignition time, namely the time from the moment being inserted into the furnace to the presence of the visible flame, was within 2$4 \mathrm{~s}$ at both $\mu-g$ and 1-g for the coal particles used in present studies. It depends on the coal properties, such as volatile matter content, heating value, size and some uncertainties in the experiments. More studies on the ignition time will be conducted in the future.

\section{Concluding Remarks}

Microgravity $(\mu-g)$ provides an ideal environment for the fundamental studies of coal ignition and combustion, but the existing studies are very limited and with questionable experimental setup and temperature measurement method. In present study initiated the first experiments on coal ignition and combustion in China, using the drop tower of NMLC. During the experiments, coal particles were heated with the conventional hot furnace while the surface temperature of the coal particles during the pyrolysis process was determined with the RGB colorimetric method. Corresponding experiments were conducted at 1- $g$ for comparison.

The experimental study explored the entire ignition process of single coal particle at $\mu-g$. The results showed that the ignition of all tested coal particles was homogeneous ignition. The shape, structure, brightness and development of the flames, as well as the interaction between volatile release and the enclosed flames during the ignition process at microgravity differed from the ones at normal gravity. At $\mu-g$, it was observed that the part of volatile was released in jets, while such a phenomenon was covered by natural convection at $1-$ $g$. At the same time after ignition, flames at $\mu-g$ were more spherical, thicker, more laminated and dimmer. It was found that ignition temperature decreased with the increasing of particle size and volatile content, agreed with what was found in the literature. However, contradicted to existing experimental results, with the same size, ignition temperature of coal particles was about $50-80 \mathrm{~K}$ lower than that obtained at 1-g. More experimental studies and modeling on the coal ignition at $\mu-g$ are strongly suggested.

Acknowledgements The support and corporation provided by NMLC are highly appreciated. This project was also supported by NFSC (No.50576041) and the National High-Tech R\&D Program of China (No.2007AA05Z303).

\section{References}

Annamalai, K., Durbetaki, P.: A theory on transition of ignition phase of coal particles. Combust. Flame 29(3-4), 193-208 (1977)

Chen, J.C., Taniguchi, M., Narato, K., Ito, K.: Laser ignition of pulverized coals. Combust. Flame 97, 107-114 (1994)

Davini, P., Ghetti, P., Bonfanti, L., Michele, G.: Investigation of the combustion of particles of coal. Fuel 75(9), 1083-1088 (1996) 
$\mathrm{Du}, \mathrm{X}$. , Annamalai, K.: The transient ignition of isolated coal particle. Combust. Flame 97, 339-436 (1994)

Essenhigh, R.H., Misra, M.K., Shaw, D.W.: Ignition of coal particle: a review. Combust. Flame 77, 3-10 (1989)

Gieras, M., Klemens, R., Wolanski, P., Wojcicki, S.: Experimental and theoretical investigation into the ignition and combustion processes of single coal particles under zero and normal gravity conditions. Proc. Combust. Inst. 21, 315-323 (1986a)

Gieras, M., Klemens, R., Wolanski, P.: Experimental and theoretical study of ignition of single coal particles at zero gravity. Acta Astronauti. 13(5), 231-239 (1986b)

Gururajan, V.S., Wall, T.F., Gupta, R.P., Truelove, J.S.: Mechanisms for the ignition of pulverized coal particles. Combust. Flame 82(2), 119-132 (1990)

Karcz, H., Kordylewski, W., Rybak, W.: Evaluation of kinetic parameters of coal ignition. Fuel 59(11), 799-802 (1980)

Katalambula, H., Kitano, K., Ikeda, K., Chiba, T.: Mechanism of ignition of single coal particle: effect of heating rate on particle-size dependence of ignition temperature. J. Chem. Eng. Jpn. 29(3), 523-530 (1996)

Katalambula, H., Hayashi, J.I., Chiba, T.: Dependence of single coal particle ignition mechanism on the surrounding volatile matter cloud. Energy Fuels 11, 1033-1039 (1997a)

Katalambula, H., Hayashi, J.I., Chiba, T., Ikeda, K., Kitano, K.: Mechanism of single coal particle ignition under microgravity condition. J. Chem. Eng. Jpn. 30(1), 146-153 (1997b)
Ronney, D.P.: In: Moti, R. (ed.) Physics of Fluids in Microgravity[C], pp. 371-431. Taylor \& Francis, London (2001)

Tognotti, L., Malotti, A., Petarca, L., Zanelli, S.: Measurement of ignition temperature of coal particles using a thermogravimetric technique. Combust. Sci. Technol. 44, 15-28 (1985)

Wei, C.Y., Li, X.D., Ma, Z.Y., Xue, F., Wang, F., Yan, J.H., Ceng, K.F.J.: Research of the numerical method of the colorimetric temperature-measurement method used in high temperature flame image process. Combust. Sci. Technol. 4(3), 307-311 (1998) (in Chinese)

Wendt, C.I.M., Ikeda, K., Katalambula, H., Kitano, K., Eigenbrod, C., Rath, H.J.: Dependence of single coal particle homogeneous ignition on particle shape under microgravity condition. Microgravity Sci. Technol. 12(2), 51-55 (1999)

Wendt, C., Eigenbrod, C., Moriue, C.O., Rath, H.J.: A model for devolatilization and ignition of an axisymmetric coal particle. Proc. Combust. Inst. 29, 449-457 (2002)

Yang, H.R., Lu, J.F., Zhang, H., Yue, G.X., Guo, Y.X.: Coal ignition characteristics in CFB boiler. Fuel 84(14-15), 1849$1853(2005)$

Zhang, X.: Research advances on microgravity combustion. Adv Mech [J], 34(4), 507-528 (2004) (in Chinese)

Zhang, D.K., Wall, F.T.: Ignition of coal particle: the influence of experimental technique. Fuel 73(7), 1114-1119 (1994)

Zhou, H.C.: Measurement Principles, and Technologies of Flame Visualization in Furnaces. Science Press, Beijing (2005) (in Chinese) 